\title{
The Secret of Internet Celebrities: A Qualitative Study of Online Opinion Leaders on Weibo
}

\author{
Ruohan Li \\ City University of Hong Kong \\ ruohanli2-c@my.cityu.edu.hk
}

\begin{abstract}
Internet celebrities are widely observable on social media platforms and are an essential component to a social media marketing program. Drawing on the media success literature and online influencer research, this study reflects Internet celebrities' fameseeking practices and discusses on three issues from literature: definition of Internet celebrities, Internet celebrities' identification criteria and what factors can contribute to individual online influence. A series of interview from three Internet celebrities and three followers of each celebrity were conducted to enrich this study. The results show that Internet celebrities are people who have become famous by means of Internet, and have the ability to influence others. They are characterized as having a certain number of followers; high level of interactivity on their profile; and promising business value. Moreover, this study suggests a five-dimensional perspective to understand individual online influence. We believe that these findings provide new insights for interpretation of Internet celebrities and suggest a possible success formula for fame-seekers to achieve influence on the increasingly competitive social media platforms.
\end{abstract}

\section{Introduction}

As social media platforms bring new capabilities to leverage people's expertise in a new way, such as realtime communication, multi-media presentation, and high-efficacy marketing functions, it has rapidly changed the dynamics of celebrity cultures. Twitter, Facebook, Instagram and Weibo, as well as short-video sharing and live streaming platforms, have all contributed to the mass production of Wanghong (Internet celebrities in Chinese) [1]. Based on their notable online influence, Chinese Internet celebrities make millions of money through e-commerce and online advertising, which they called "turn online traffic into money". According to $\mathrm{CBN} \mathrm{Data}^{[1]}$, the "Wanghong economy" is set to be worth 58 billion Yuan in 2016, more than China's box office in 2015 [2]. Because of profitable financial rewards of being an Internet celebrity, a rising number of fame-seekers participate in the "do-it-yourself" celebrity plan that refers to ordinary people emerge as Internet celebrities when they share valuable information on social media platforms [4].

Internet celebrities are important because of their so-called celebrity status and their influence on their followers. For example, in social media marketing activities, Internet celebrities can forward or directly post promoted information, provide recommendations, give personal comments through their social media account to create a buzz and make an endorsement, which can shape their follower's interest. Because of this persuasive impact, researchers have proposed various techniques to identify Internet celebrities who have the influential power. A fundamental principle emphasizes on the number of followers - social media user with a large number of followers represents a higher level of influence on social media platforms $[21,22]$. However, the number of followers indicates individual popularity; it is not necessarily related to his/her influence [5]. Even if lots of techniques for the analysis of individual influence on social media platforms have been proposed $[23,24,25,26]$, the study of identification of Internet celebrities is faced with various challenges. Firstly, being a highly subjective area, it is difficult to qualify the distinctive characteristics of individual online influence and propose reasonable measures [27]. The quantifiable definition of individual online influence seems to be merely surface features [28]. Moreover, individual online influence is mainly time- and event-driven concept [29]. As a number of hot topics and new influential users appear every day, the influence of social media user dynamically changes over time [29].

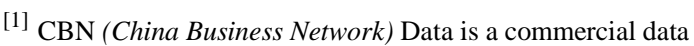
company affiliated with Alibaba.
} 
Thus, the varied time and event make the quantification of online influence more complex [27]. Given the recognition that individual influence on social media platforms is about quality, not quantity [31,32]; researchers call for more subjective and detailed understanding of the assessment of Internet celebrities who have influential power online [28].

To this aim, our study focuses on Chinese Internet celebrities (Wanghong) on social media platforms, by examining the following research questions: (1) Who can be considered as Internet celebrities (Wanghong) on social media platforms? (2) What factors contribute to Internet celebrities' online influence? We attempt to provide a comprehensive understanding of Internet celebrities and explain online influence of Internet celebrities based on their ability to provide certain values for audiences. Inspired by Du and Wagner's the weblog success model [8], and the study of emotional value [9], we proposed individual online influence could be understood from a value-based proposition. We adopted interviews with three Internet celebrities and three followers of each celebrity to enrich this study. The paper is organized as follows. Literature review part provides a systematic review of the related studies of Internet celebrities and the media success literature to understand online influence of a social media user from a value-based proposition. Methodology part clearly demonstrates the research design of this study, how we developed the interview protocol, how we selected the proper informants and how we conducted the interview. We also suggest the findings and the contributions as the conclusion.

\section{Literature reviews}

\subsection{Internet celebrities (Wanghong)}

The advent of social media has brought a new type of celebrity. People who are not well recognized in real life could utilize Internet to perform as Internet celebrities. This new type of celebrity involves the practice of self-presentation on social media, which is presented by the creation of unique online image and the use of image to attract online eyeball $[7,30]$. Yet, people who have online influence on others have appeared for years, there is no widely accepted term and specific definition to describe them. Researchers have used different labels to depict this new type of celebrity, including social media influencers (SMIs) [25,28], influential bloggers [14], famous Instagram bloggers [7] or YouTube stars [10]. In China, no matter what social media platforms they emphasized on, people who have achieved influence based on the use of Internet have a unified name-Internet celebrities
(Wanghong) [2]. They can range from would-be or unknown actors/actresses, experts in a specific field, for example, fitness trainers or photographers, and wealthy people who would love to show off their luxuries to young girls have pretty face $[7,11,12]$. While the label or actual identity differs, Internet celebrities all disclose their personal lives [12] and exhibit influence to a large number of followers [30] on social media platforms. Some of the most successful Chinese Internet celebrities (Wanghong) have earned their living based on their online influence [2]. Internet celebrities have been deemed as trusted members of their own online community; their followers rely upon them for information, news, and opinion [13]. In this study, we describe Internet celebrities as a kind of online opinion leaders who were likely to influence other persons on social media platforms.

\subsection{Measuring influence of Internet celebrities from a value-based proposition}

It is not easy to achieve influence online since not all the ideas appear online would be equally interesting and valuable [25]. Prior studies have researched the success of many emerging online interactive media applications. For example, how to make weblog success online [8]. The weblog success model proposed by $\mathrm{Du}$ and Wagner attributes a weblog's success to its ability to offer certain values for audiences/readers. The first value factor refers to the content value, the information itself, like any other forms of web content [8]. Content type, posting volume/frequency, and writing style would affect the content value. The second value factor is technology that used to present content and initial social interaction [8]. Multimedia capability of social media platforms displays a very different effect than text content and it facilitates the interaction among users. Another important value factor is regarded as the social resources established on weblog. In addition to the aforementioned value factors from weblog success model [8], emotional value that is characterized as the aggregated feeling of goodwill also plays an important role in social media success within organizations [9]. From a marketing perspective, providing values for customers and potential customers could enhance purchase interest [33]. However, Social media users invest in time, feelings and emotions rather than the economic motivation in shopping behavior [34], they interact with others with the expectation of getting some values in return [3]. Thus, we propose that individual online influence could be understood from a value-based proposition. Based on the findings from Du and Wagner's the weblog success model [8], and the study of emotional value [9], this study aims to 
interpret individual success (Internet celebrities who have influential power online) from a value-based proposition. It is reasonable that Internet celebrities provide different values for their followers to maintain online influence, for instance, they might offer highquality content, no matter useful or entertaining; utilize proper technological functions to conduct selfpresentation; maintain a close social relationship and build emotional bonds with others and so on. Thus, we consider the online influence of Internet celebrities relates with their ability to provide values for their followers.

\section{Methodology}

As a micro-blogging website, Weibo combines social media and e-commerce characteristics [15], which largely helps Internet celebrities to promote activities and themselves. Through providing useful tips and advice, Internet celebrities play an important role in shaping people's attitudes and act like a trustful advisory on Weibo [16]. Therefore, Weibo is an ideal platform to investigate research questions on online influence of Internet celebrities. We conducted interviews with Internet celebrities and their followers directly to understand online influence of Internet celebrities. Interview approach aims to strengthen relations between academia and industry, which brings theory closer to real practices [36]. It allows us to identify more subjective insights about the influence of Internet celebrities from Internet celebrities' sides and their followers' sides. Inspire by the study of [37], to find out how to define Internet celebrities, we send interview invitations using the direct message function (DMs) on Weibo to potential respondents who are identified as Internet celebrities based on the classification of influencer on social media [38]. Even if this classification is made on the basis of the number of followers, the number of followers may not fully represent online influence [29], it is still valuable to help us to find potential respondents. In this classification, differences in the number of followers represent the different online influence. Internet celebrities who have 1000 to 100,000 followers are characterized as the up-and-coming category; Internet celebrities who have more than 100,000 followers are described as the popular category; Internet celebrities who have more than 1 million followers indicate the highest online influence. This purposeful sampling from different categories maximized the depth and the richness of the data [41]. We received six responses through direct messages to our interview invitations and three of them agreed to participate in interviews. Fortunately, those three participants are from the three categories respectively, which means each target category has responses. After the interview with Internet celebrities, we asked them to recommend us three of their followers as respondents from follower side. For the validation of data, triangulation across resources $[39,40]$ was realized through interviews held with Internet celebrities and their followers with different backgrounds and demographic information (as shown in Table 1). Using an individual semistructured interview protocol, each participant was asked a series of open-ended questions based on the research questions: (1) Who can be considered as Internet celebrities (Wanghong) on social media platforms? (2) What factors contribute to Internet celebrities' online influence? We rely on measurement items from the weblog success model [8], and attributes of emotional value [9] as interview questions to measure what factors may affect online influence of Internet celebrities. Interviews with participants were conducted individually in Chinese, by using instant message application with audio chat function, WeChat. Each interview lasted for approximately 30 minutes. All interviews were audio recorded and accompanied with written notes to avoid difficulties later in the transcription and coding process. The interview audio recordings were transcribed into text by using a speech recognition software, iFLYTEK Open Platform. The author also manually checks the accuracy of the transcription. The transcription has been translated in English and checked for validity by two Chinese background researchers. The coding process is shown as the following steps: Firstly, authors open-coded the interview transcription to gain general expressions that are based on their units of meaning [55] Then, codes were assigned according to the themes indicated in the participants' own description, which is called in vivo coding technique [17]. Then, the axial coding was performed to identify the connections among the codes and further summarized the similarities and differences, as suggested by [20] in order to classify data under relevant groups. The results are discussed in the following section.

Table 1. Basic information of Internet celebrities and the ir followers

\begin{tabular}{llll}
\hline Identifier & Gender & Age & \\
\hline $\mathrm{A}(12,000+)$ & Female & 25 & $\begin{array}{l}\text { Share } \\
\text { make up/fashion } \\
\text { tips }\end{array}$ \\
$\mathrm{B}(170,000+)$ & Male & 29 & $\begin{array}{l}\text { Share the life of } \\
\text { his pets }\end{array}$ \\
$\mathrm{C}(2,180,000+)$ & Female & 27 & $\begin{array}{l}\text { Share jokes, } \\
\text { and daily life }\end{array}$
\end{tabular}




\begin{tabular}{llll} 
A1 & Female & 19 & $\begin{array}{l}\text { Student } \\
\text { A2 }\end{array}$ \\
A3 & Female & 24 & Student \\
B1 & Female & 26 & $\begin{array}{l}\text { Purchasing } \\
\text { agent }\end{array}$ \\
B2 & 19 & Student \\
B3 & Female & 21 & Student \\
C1 & Female & 20 & Student \\
C2 & Female & 24 & $\begin{array}{l}\text { Purchasing } \\
\text { agent }\end{array}$ \\
C3 & Female & 28 & Administrator \\
& Female & 24 & Volunteer of \\
& & & NGO \\
\hline
\end{tabular}

\section{Results}

The extracts from the interviews are examined under two main questions: (1) Who can be considered as Internet celebrities on social media platforms? (2) What factors contribute to Internet celebrities' online influence? The common points are summarized in Table 2. Additionally, other specific findings are explained in this section.

\subsection{Definition of Internet celebrities}

Although every interviewee holds different opinions about the definition of Internet celebrities, all of them indicated that Internet celebrities are content creators who have the power to affect behavior and attitudes of others on social media platforms. Internet celebrities are considered as opinion leaders on Weibo. This result is consistent with prior research that opinion leaders have "the power to alter decisions of others because of their authority, knowledge, position or relationship" $[13,18,19]$. One participant from Internet celebrities' side gives the following statement: "Internet celebrities bring an influence to their followers, what they post online is authoritative, which means his content will cause discussion and will become a hot topic online." Four of the twelve participants claim Internet celebrities are someone who has become famous by means of the Internet, due to the proliferation of social media platforms. Comparably, two mentioned that ordinary people could utilize social media platforms to attract online attention; the development of social media has lowered the requirements for becoming a celebrity. The majority of respondents categorize Internet celebrities based on what kinds of content they provided on Weibo: Foodrelated; Pet-related; Fashion-related; Joke-related, etc. In addition, some of the participants emphasize how they produce the content, dividing them into two types: originator and re-blogger. The former, who produce all of content by themselves, normally give insightful advice/tips and useful information based on their expertise in specific fields. Re-blogger refers to "copy and paste" people who transfer popular content on other social media platforms to Weibo. Five respondents classify Internet celebrities based on their economic power: making profits or non-making profits. Internet celebrities who making profits have already turned their online fame into real cash by online retailing or publishing endorsement message on their Weibo account. Regardless of their categorization of Internet celebrities, all participants point out several essential criteria when they defined Internet celebrities on Weibo. Therefore, identification criteria of Internet celebrities are separately analyzed in the section below.

\subsection{Internet celebrities' identification criteria}

The interviewed participants list various identification criteria based on their own impression about Internet celebrities:

The number of followers: One of the essential criteria for identifying Internet celebrities is the breadth of their networks on social media platforms. The majority (9 of 12) of respondents mention the number of followers could identify who are Internet celebrities: One participant from followers' side states: "He or she must attract a certain amount of attention, which means he or she has lots of followers. The number of followers represents the level of recognition from others." In contrast with the majority, who agree on this measurement of Internet celebrities, three interviewees strongly disagree this criterion, an Internet celebrity participant who has a different perspective: "The number of fans should not be a criterion because of too much water army (fake accounts) on Weibo." Another follower participant further explains: "I feel the number of followers doesn't mean all of those followers really like him. Followers are not equal to fans." Thus, some of respondents also suggest the level of interactivity could represent whether a social media user is an Internet celebrity.

The level of interactivity: Interactivity is one of the unique defining features of engagement with online information [42]. Six among twelve interviewees of our study mention the number of re-post/comment/like of single message posted by a micro-blogger represents the level of interactivity of this message, which further indicates the ability of a micro-blogger to engage 
his/her followers. One participant from Internet celebrities' side describes: "we can look at the level of interactivity on his/her Weibo account, which means how many comments and re-post, like he/she received. Whether his/her followers have a good loyalty to him/her. In general, if there are lots of people interact/communicate on his/her Weibo account, and followers are willing to chat with the content creator, to participate in the topic raised by the content creator, he/she can be perceived as an Internet celebrity."

Business potential: As China's Internet celebrity economy rising in 2016 [43], the business potential of a social media user could be a unique feature to evaluate whether he or she qualified to be an Internet celebrity. Five participants support this argument. One participant from Internet celebrities' side expresses 'If you can attract advertiser's attention, they think you can be an endorser of their products, you are an Internet celebrity. For example, the commercial value of yourself, if you can make money 10,000-20,000 RMB per month through Weibo, I think you are an Internet celebrity." One follower participant claims: "Internet celebrities are people who operate online shop on Taobao and conduct advertising on Weibo. Internet celebrities also would like to communicate with their followers by using live streaming platforms, their followers can donate money to them or send virtual gifts. The huge amount of money they earned online can represent whether they are Internet celebrities." Other follower participant further mentions: "I am so glad to see they make a product endorsement online! This means they finally draw attention from the advertiser, they finally become famous enough to do adverting for others!" This eyecatching finding here is the business value could be considered as one characteristic of Internet celebrities, which differs from previous research that the monetized recommendation may cause bad impression online and sacrifice online reputation [44].

Apart from those three major identification criteria, one follower expresses the accidental of how they become famous on social media platforms: "I think Internet celebrities are people who suddenly become famous online, because of a thing or some action." In addition to online influence of Internet celebrities, an Internet celebrity mentions offline influence of Internet celebrities: "Internet celebrities are people who become famous online, but their offline reputation also is important. When you hang out with your friends, and you guys talk about an Internet celebrity, everybody should know him/her."

Table 2. Major findings of interviews

Topics Common Points Participants

\begin{tabular}{|c|c|c|}
\hline \multirow{2}{*}{$\begin{array}{l}\text { Definition of } \\
\text { Internet } \\
\text { celebrity }\end{array}$} & $\begin{array}{l}\text { Opinion leaders } \\
\text { on Weibo; }\end{array}$ & All of participants \\
\hline & $\begin{array}{l}\text { Someone who } \\
\text { has become } \\
\text { famous by } \\
\text { means of the } \\
\text { Internet }\end{array}$ & $\mathrm{A} 3, \mathrm{~B} 1, \mathrm{C} 2, \mathrm{C} 3$ \\
\hline \multirow{4}{*}{$\begin{array}{l}\text { Internet } \\
\text { ce le brities' } \\
\text { identification } \\
\text { crite ria }\end{array}$} & $\begin{array}{l}\text { Number of } \\
\text { followers; }\end{array}$ & $\begin{array}{l}\mathrm{C}, \mathrm{A} 1, \mathrm{~A} 2, \mathrm{~A} 3, \mathrm{~B} 1, \mathrm{~B} 3, \\
\mathrm{C} 1, \mathrm{C} 2, \mathrm{C} 3 ;\end{array}$ \\
\hline & $\begin{array}{l}\text { The le vel of } \\
\text { Interactivity; }\end{array}$ & $\mathrm{C}, \mathrm{A} 2, \mathrm{~B} 1, \mathrm{~B} 2, \mathrm{~B} 3$, \\
\hline & D & C3; \\
\hline & Dusiness value & $\mathrm{A}, \mathrm{B}, \mathrm{A} 3, \mathrm{C} 1, \mathrm{C} 3$ \\
\hline
\end{tabular}

\subsection{What factors contribute to online influence of Internet celebrities?}

The results show multifaceted factors could affect online influence of Internet celebrities, including Internet celebrities' ability to provide value for their followers at content, technology, social, emotional, and symbolic levels. The following sections summarize those factors and offer a detailed interpretation of each factor:

Content value: When we discuss what factors affect their online influence, participants attribute Internet celebrities' power to various factors, content provided by Internet celebrities is considered as a major reason, which is consistent with $\mathrm{Du}$ and Wagner's argument that blogs success depends on the content value it provides for its readers [8]. This consensus among all participants, one participant from Internet celebrities' side mentions the need for Internet celebrities to increase the attractiveness of their content, she describes: "I often ask my followers what kinds of content they want to see. If you want to get someone's attention, the most important thing is that you can provide interesting content. So I think the content is the most important. The more attractive content you present, the more attention you get, and the more influence you achieve." One of the participants from followers' side, claiming that content provided by Internet celebrities is not necessary to be knowledgeable, but should be interesting, explains this situation as "For example, there is something very funny happening to me. She can present this thing in an interesting way while I can't, which means she is good at organizing language."

Technology value: Participants from Internet celebrities' side also emphasize a different dimension, the built-in technological affordances of social media platforms. The technology contribution in achieving 
online influence of an Internet celebrity could be considered by its ability to present content, and to facilitate social interaction among users. One Internet celebrity participant underlines the importance of technology value, particularly for the role of technology integration: "To enhance my online influence, I would like to use multi-media functions to present content. First of all, I love video! It has a better sensory and visual effect, which is much better than text. Also, image with text is my second choice, actually, video costs lots of cellular, not everyone would like to click your video." Another insightful participant from Internet celebrities' side also givea an example of leveraging followers' engagement by using technological feature: "I love to use the live-streaming video to present myself; I received lots of new followers because of it. Visual gives people an illusion of encounter. People love the real-time communication." Several follower participants also highlight the power of technology, the interesting common point is: Weibo has a special function that other social media platforms do not have, which is Weibo user can post comments with pictures or emoticon. Sometimes Internet celebrities would reply their followers with emoticon and pictures, it generates much funnier story than the published Weibo (content) itself.

Social value: According to one participant from Internet celebrities' side, Internet celebrities need to make their followers have the feeling of "you care about them", which contributes to building long-term relationships. The findings reveal different approaches to building and sustaining relations, for instance, Internet celebrities can frequently reply their followers' comments to "perform connection and availability" [44], which gives back to loyal followers. One Internet celebrities' participant emphasizes her efforts on maintaining relationships: "I replied their comments a lot; I interacted with them through live-streaming video to show them my personal life. I also established an online chat group on Wechat so that followers can communicate with others and we chatted together." Moreover, Internet celebrities need to maintain the social relations with other famous Internet celebrities to gain public recognition or to show their identity- "I belong to the Internet celebrities circle". An Internet celebrity participant indicates that she pays more attention to sustain relationships with other Internet celebrities: "If you cannot present the attractive content, and your follower number is limited, what you post online can only be perceived by few people. But if you ask other Internet celebrities who have much more followers than you to re-post your content, it will largely increase the exposure of content and show the friendship between you guys." There is also a consensus on social value from follower side. One follower participant states: "If she replies my comments or interacts with me when she is doing a live video streaming, I will feel that I'm the chosen one.", which is consistent with the finding of [44]. If someone receives comments and @ from celebrity, the interactions between them function as a mark of status and are publicized within the follower community [44].

Emotional value: Our results corresponds to arguments presented by Huy and Shipilov regarding emotional value as the key to social media success within organizations [9]. They argue emotional value as the aggregated feeling of goodwill, for example, authenticity, pride, attachment, and fun. Each participant agree on the importance of emotional value provided by Internet celebrities on attracting other attention, one participant from followers' side indicates: "She (Internet celebrities) is very authentic, just like a good friend in my real life. I feel no distance with her." However, the follower participates all have the same mind, that it is difficult to directly measure whether Internet celebrities are presenting the real self or just role playing to do "impression management" [45]. One participant from Internet celebrities' side confirms this point: "All of the output of contents, the application of technology, social networking and relationships are intended to mold a personal image on social networking. Molding a personal image on Weibo also cost me a lot of energy, which is like role-playing. Some of followers yearn for seeing my life. Actually, I just show a very little part of me which is molded and selected."

Symbolic value: When people consume a product, he/she will consume things that hold particular symbolic meanings. For instance, using recycled envelopes may symbolize "I care for the environment." [46]. Internet celebrities structure themselves as the tag of

"fashion/beautiful/independent/knowledgeable/humoro us.", coding themselves in the various ways of posting text/audio/video [47] on social media platforms. Personal characteristic of Internet celebrities, such as appearance and personality, contributes to the formation of unique identity, which can attract others' attention. All of Internet celebrities' participants point out that regularly updating content with their unique personal style has a positive effect on attracting others attention and enhancing influence, summed up in the following statement: The contents, the use of technology, the maintaining of social relationships is set according to the distinctive image that you want to present. On the other hand, followers would decode those symbolic activities presented by Internet celebrities based on their preference in the process of interaction. This decoding refers to symbolic 
interactionism, which maintains that meaning is constructed through language, interaction, and interpretation $[48,49]$. One participant from followers' side describes her feeling: "I quite like her, her face, her voice, her make-up and her dressing style. By following her, it gives me a kind of feeling that I am also a fashionable person." Another follower further mentions, "I hope I can be a person who is like him when I am at his age. Well, I mean I could think and bear myself in the same way."

\section{Implications}

\subsection{Theoretical implications}

To better understand Internet celebrities on social media platforms, this study contributes to the literature at the following aspects: Firstly, we proposed to define Internet celebrities a kind of online opinion leaders who were likely to influence other persons on social media platforms, the interview results confirmed our argument. Previous literature on the identification of online influential user mainly adopts objective data. Yet, the concept of individual online influence is highly subjective; it is hard to be quantified into a measure [29]. In this study, we provide interpretative, detailed understanding of Internet celebrities to comprehend individual online influence. To sum up, the recognized Internet celebrities should have following characteristics: a certain number of followers; high level of interactivity on their profile; and promising business value. They have been described as content creators or re-bloggers, profit-makers by means of Internet, and influential online opinion leaders who shape others' attitude. Secondly, our study extends existing media research by identifying the possible effect of symbolic value on individual online influence. Previous media success theory mainly focuses on the impacts of content [8], of technology [51], of social resources [52] on the success of media. However, with the development of technology and the monetized society at present, prior studies might overlook other attention-getting elements that contribute to media/individual success. To the best of our knowledge, the present investigation is one of the pioneering research that takes the symbolic meaning of a person into consideration in the domain of online influence. We identified that social media users consider the image of Internet celebrities as commodities, thus, they decode those symbolic meaning in the process of interaction according to their preference, which influence their self-identification reversely. Lastly, we suggest a five-dimensional perspective to understand online influence of Internet celebrities. We argue that individual online influence is relevant to his/her ability to provide values for audience at content, technology, social, emotional and symbolic level. Even if some of the value-based factors originate from previous media success theory [8,9], we consolidate the previous research findings and our results together into this five value-based dimensions to evaluate individual online influence.

\subsection{Practical implications}

Although the commercial effects of Internet celebrities have been extensively identified, little is known about the definition and approachable identification criteria of Internet celebrities. Consequently, it is difficult for brand managers to directly identify and select proper Internet celebrities to participate in commercial activities online. Moreover, despite the rising number of fame-seekers practice online, most practitioners never achieve a high level of online influence. The lack of a guideline for practitioners in the previous literature might also be detrimental because many fame-seeking practitioners conduct extreme behaviors for seeking online influence [50]. The findings of this study could provide insights for fame-seeking practitioners to better understand how Internet celebrities utilize social media platforms. It leads to practical implications for fame-seeking practitioners regarding the creation of content, the use of technology, the maintaining of social relations, the presentation of goodwill, and the formation of distinguishing image on social media platforms. First, practitioners need to provide very attractive content for audience, no needs to be knowledgeable but be interesting, which is consistent with the importance of content in blogosphere [8]. Moreover, changes in the social media platforms caused by technological developments have affected how social media users produce content [53,54], fame-seeking practitioners should gain a full understanding of the unique technological characteristics of the selected social media platform in order to achieve a successful presence. Furthermore, fame-seeking practitioners should not ignore the influence of social media messages, comments, and reviews. The interactions between followers and Internet celebrities and relationships with other Internet celebrities need to be carefully maintained. Additionally, fame-seeking practitioners have to provide emotional value as the aggregated feeling of goodwill, to emphasize commonalities, to create a sense of closeness and familiarity between themselves and their followers. This enables followers could respond with them with no pressure, to feel no distance, to generate intimacy. Finally, yet importantly, the formation of a distinctive 
personal image is quite important to enhance online influence, because symbolic consumption becomes a considerable trend, which is driven by the young people [47]. Internet celebrities' unique image signify different meaning for their followers, which affects the construction of self-image of followers in return. In addition to practical application for fame-seeking practitioners, the five value-based dimensions also could be implemented into the maintaining of online influence for Internet celebrities who have already achieved online influence. Individual online influence on social media are dynamic [27], it is mainly timeand event-driven concept [29]. The changed online influence also ties into Andy Warhol's statement about 15 minutes of fame: "In the future, everyone will be world-famous for 15 minutes" [6]. Thus, this study could provide guideline for Internet celebrities to keep providing value for their followers. To sum up, this study suggests a potential success formula for practitioners who would like to chase fame on social media platforms and a maintaining mechanism for Internet celebrities who have already achieved online influence, by recognizing five value-based dimensions.

\section{Limitations and further research}

These results show the subjective, detailed understanding of Internet celebrities, the identification criteria, and the five value-based dimensions that contribute to online influence. However, the current study is limited given that it is based on only 12 interviews and uses a limited sample, three Internet celebrities' participants and nine followers' participants. Moreover, all of participants from followers' side are female, and five among nine are students, which might lead to data bias. Future research should look to engage more respondents from different gender and occupation to generate insightful results. Even if we bring the five value-based dimensions together to understand individual online influence, we did not propose the operational definitions of them and test the relationship between them. Further research using a larger participants group, and different methods would also address the statistical significance limitations of this study. Additionally, individuals are characterized by multiple community memberships in today's digital era [35]. In order to enhance the generalizability of those five value-based dimensions of online influence, it is necessary to investigate how Internet celebrities utilize different social media platforms to attract attention and exhibit influence.

\section{Conclusion}

With the rise in popularity of social media platforms, much hope has been expressed about ordinary people being famous online to gain economic value. Millions of people publish content on social media platforms, these contributions rarely make them notable on a large scale. Few people can become real celebrities who have the ability to influence others on Internet. For fame-seekers who want to achieve influence online, the key challenge is how to effectively attract other social media users' attention. In this qualitative study, we try to find out the secret of Internet celebrities that refers to what factors make them success (in terms of achieving online influence) on social media platforms. The results recognize that Internet celebrities provide followers with unique content, visualized technology, and close social relationship, which contributing their online influence. Moreover, as they are building the celebrity-fans relationship, it is necessary to pay attention to developing emotional bonds and building a distinctive image of celebrity. Internet celebrities who have already had the influence to consider how to maintain their online influence also could utilize this fivedimensional perspective. Additionally, this study provides subjective understanding of Internet celebrities and their identification criteria, thus, marketers can easily identify and select Internet celebrities and take necessary marketing action based on Internet celebrities' online influence.

\section{References}

[1] G. Turner, "Approaching celebrity studies", Celebrity Studies, 1(1), 2010, pp.11-20.

[2] CBN Data, "Wanghong economy Report of 2016", Retrieved from http://cbndata.com/report/69, 2016.

[3] M.K. Lee, C. M. Cheung, K. H. Lim, and C. L. Sia, "Understanding customer knowledge sharing in web-based discussion boards: An exploratory study", Internet Research, 16(3), 2006, pp.289-303.

[4] W. W. Xu, Y. Sang, S. Blasiola, and H. W. Park, "Predicting opinion leaders in Twitter activism networks: The case of the Wisconsin recall election", American Behavioral Scientist, 58(10), 2014, pp.1278-1293.

[5] C. Bigonha, T. N. Cardoso, M. M. Moro, V. A. Almeida, and M. A. Gonçalves, "Detecting evangelists and detractors on twitter". In 18th Brazilian Symposium on Multimedia and the Web, 2010, pp.107-114.

[6] "Andy Warhol's Fifteen Minutes", Retrieved from http://www.warholstars.org/warhol/warhol1/andy/warhol/fil m/tv.html,2017.

[7] A. E. Marwick, "Instafame: Luxury selfies in the attention economy", Public Culture, 27(1), 2015, pp.137-160. [8] H. S. Du, C. Wagner, "Weblog success: Exploring the role of technology", International Journal of HumanComputer Studies, 64(9), 2006, pp.789-798. 
[9] Q. Huy, A. Shipilov, "The key to social media success within organizations", MIT Sloan Management Review, 54(1), 2012, pp.73.

[10] R. Berryman, M. Kavka, “I Guess A Lot of People See $\mathrm{Me}$ as a Big Sister or a Friend': the role of intimacy in the celebrification of beauty vloggers", Journal of Gender Studies, 26(3), 2017, pp.307-320.

[11] C. Abidin, "Aren't these just young, rich women doing vain things online?: Influencer selfies as subversive frivolity", Social Media+Society, 2(2), 2016.

[12] H. Saul, "Instafamous: Meet the social media influencers redefining celebrity", The Independent, Retrieved fromhttp://www.independent.co.uk/news/people/instagramm odelnatasha-oakley-iskra-lawrence-kayla-itsines-kendalljenner-jordyn-woodsa6907551.html, 2016.

[13] Y. Jia, L. Liu, "Who do we listen to more: Opinion leaders or friends? The social function of conformity behavior in social commerce. In Proceedings of the 50th Hawaii International Conference on System Sciences, 2017.

[14] E. Uzunoğlu, S.M. Kip, "Brand communication through digital influencers: Leveraging blogger engagement", International Journal of Information Management, 34(5), 2014, pp.592-602.

[15] H. T. HO, "Sina Eeibo and twitter: A clone or a reverse?”, Cultural Studies@Lingnan, 52(1), 2016.

[16] W. Chen, "How well do you know about China's online celebrity economy", Retrieved from https://www.linkedin.com/pulse/how-well-do-you-knowchinas-online-celebrity-economy-claire-chen, 2016.

[17] J. Saldaña, The Coding Manual for Qualitative Researchers, Sage, 2015.

[18] Influencers. BusinessDictionary.com. Retrieved from BusinessDictionary.com website: http://www.businessdictionary.com/definition/influencers.ht $\underline{\mathrm{ml}}, 2017$.

[19] A. Burke-Garcia, C. N. Berry, G. L. Kreps, and K. B. Wright, "The power \& perspective of Mommy Bloggers: Formative research with social media opinion leaders about HPV vaccination", In Proceedings of the 50th Hawaii International Conference on System Sciences, 2017.

[20] D. Carson, A. Gilmore, C. Perry, and K. Gronhaug, Qualitative Marketing Research, Sage, 2001.

[21] G. Rattanaritnont, M. Toyoda, and M. Kitsuregawa, "Characterizing topic-specific hashtag cascade in twitter based on distributions of user influence". In Asia-Pacific Web Conference, Springer Berlin Heidelberg, 2012, pp. 735742.

[22] S. Wu, J. M. Hofman, W.A. Mason, and D. J. Watts, "Who says what to whom on twitter", In: Proceedings of the 20th International Conference on World Wide Web. ACM, 2011. pp.705-714.

[23] P. Sharma, U. Khurana, B. Shneiderman, M. Scharrenbroich, and J. Locke, "Speeding up network layout and centrality measures for social computing goals", In Social Computing, Behavioral Cultural Modeling and Prediction, Springer Heidelberg, Berlin, 2011, pp.244-251. [24] J. Wang, J. P. Zeng, B. H. Zhou, and C. R. Wu, "Online forum opinion leaders discovering method based on clustering analysis", Computer Engineering (in Chinese), 37(5), 2011, pp.44-46.
[25] E. Lahuerta-Otero, R. Cordero-Gutiérrez, "Looking for the perfect tweet. The use of data mining techniques to find influencers on twitter", Computers in Human Behavior, 64, 2016, pp.575-583.

[26] Y. M. Li, C. Y. Lai, and C. W. Chen, "Discovering influencers for marketing in the blogosphere", Information Sciences, 181(23), 2011, pp.5143-5157.

[27] H. U. Khan, A. Daud, U. Ishfaq, T. Amjad, N. Aljohani, R. A. Abbasi, and J. S. Alowibdi, "Modelling to identify influential bloggers in the blogosphere: A survey", Computers in Human Behavior, 68, 2017, pp. 64-82.

[28] K. Freberg, K. Graham, K. McGaughey, and L. A. Freberg, "Who are the social media influencers? A study of public perceptions of personality", Public Relations Review, 37(1), 2011, pp.90-92.

[29] N. Agarwal, D. Mahata, and H. Liu, "Time-and EventDriven Modeling of Blogger Influence" In Encyclopedia of Social Network Analysis and Mining, Springer New York, 2014, pp. 2154-2165.

[30] K. Susie, L. Ang, R. Welling, "Self-branding, "microcelebrity' and the rise of Social Media Influencers", Celebrity Studies, 8(2), 2017, pp.191-208.

[31] D. Basille, "Social media influencers are not traditional influencers." Retrieved from http://www.briansolis.com/2009/11/socialmediainfluencersare-not-traditional-influencers/, 2009.

[32] B. Straley, "How to: Target social media influencers to boost traffic and sales". Retrieved from http://mashable.com/2010/04/15/social-media-influencers/, 2010.

[33] M. B. Holbrook, "Customer value and autoethnography: subjective personal introspection and the meanings of a photograph collection", Journal of Business Research, 58(1), 2005, pp.45-61.

[34] C. J. Keng, H. Y. Ting, "The acceptance of blogs: using a customer experiential value perspective", Internet Research, 19(5), 2009, pp. 479-495.

[35] R. P. Bagozzi, M. Bergami, G. L. Marzocchi, and G. Morandin, "Customer-organization relationships: Development and test of a theory of extended identities", Journal of Applied Psychology, 97(1), 2012, pp.63-76.

[36] D. J. Reibstein, G. Day, and J. Wind, "Guest editorial: is marketing academia losing its way?", Journal of Marketing, 73(4), 2009, pp.1-3.

[37] A. E. Marwick, D. Boyd, "I tweet honestly, I tweet passionately: Twitter users, context collapse, and the imagined audience", New Media \& Society, 13(1), 2011, pp.114-133.

[38] Z. Jade, "How Many Fans Does It Take to Become a Profitable Influencer?" Retrieved from https://hireinfluence.com/blog/how-many-fans-does-it-taketo-become-a-profitable-influencer/, 2017.

[39] N. K. Denzin, Sociological methods: A sourcebook. Butterworths, London, 1970.

[40] R. W. Belk, M. Wallendorf, and J. F. Sherry, "The sacred and the profane in consumer behavior: Theodicy on the odyssey", Journal of Consumer Research, 16(1), 1989, pp.1-38.

[41] A. J. Kuzel, "Sampling in qualitative inquiry", In B. F. Crabtrree, \& W. L. Miller (Eds.), Doing qualitative research 
(2nd ed.), Sage Publications, Thousand Oaks, CA,1970, pp. 33-45.

[42] M. Deuze, "The web and its journalisms: considering the consequences of different types of news media online", New Media \& Society, 5(2), 2003, pp.203-230.

[43] G. Tsoi, "Wang Hong: China's online stars making real cash", Retrieved from http://www.bbc.com/news/world-asiachina-36802769, 2016.

[44] A. E. Marwick, D. Boyd, "To see and be seen: Celebrity practice on Twitter", Convergence, 17(2), 2011, pp.139-158.

[45] E. Goffman, The Presentation of Self in Everyday Life, Doubleday Anchor Books, Garden City, NY, 1959.

[46] H. Jeong, Z. Néda, and A.L. Barabási. "Measuring preferential attachment in evolving networks", EPL (Europhysics Letters), 61(4), 2003, pp.567.

[47]Wikipedia, "Wanghong economy", Retrieved from https://en.wikipedia.org/wiki/Wanghong_economy\#cite_note $\underline{-3}, 2017$.

[48] H. Blumer, Society as symbolic interaction. In: Rose AM (ed.) Human Behavior and Social Processes. MA: Houghton Mifflin, Boston, 1962, pp.179-192.

[49] A.L. Strauss, Continual Permutations of Action Aldine De Gruyter, New York, 1993.

[50] "When People Live-Stream Murder and Suicide, Who Watches?", Broadly, Retrieved from https://broadly.vice.com/en_us/article/3k88z3/live-streammurder-suicide-periscope-facebook, 2017.

[51] J. Preece, "Sociability and usability in online communities: Determining and measuring success", Behaviour \& Information Technology, 20(5), 2001, pp.347356.

[52] K. Y. Lin, H. P. Lu, "Why people use social networking sites: An empirical study integrating network externalities and motivation theory", Computers in Human Behavior, 27(3), 2011, pp.1152-1161.

[53] S. Gensler, F. Völckner, Y. Liu, and C. Wiertz, "Managing brands in the social media environment", Journal of Interactive Marketing, 27(4), 2013, pp.242-256.

[54] D. Kuksov, R. Shachar, and K. Wang, "Advertising and consumers' communications", Marketing Science, 32(2), 2013, pp.294-309.

[55] U. Flick, "Qualitative Research-state of the Art", Social Science Information, 41(1), 2002, pp.5-24. 